\title{
SELF-MEDICATION
}

\section{AND THE PHARMACEUTICAL SYSTEM IN CAMBODIA}

\section{Eve Bureau-Point, Carine Baxerres and Sena Chheang}

\begin{abstract}
Based on an ethnographic study of the Cambodian pharmaceutical system conducted in an urban and a rural setting between January 2015 and June 2016, we report on the complex dynamics surrounding the issue of self-medication in that country. We describe the history of the circulation of pharmaceuticals in Cambodia, and we discuss the contemporary relationship individuals have with these medicines and with those who distribute them. We illustrate the specific dynamics of the pharmaceuticalization of Cambodian society, where private drug vendors are playing a key role.
\end{abstract}

Keywords: Cambodia, autonomy, pharmaceutical system, self-medication.

Media teaser: How does the Cambodian pharmaceutical system shape practices of selfmedication?

\section{Bionotes}

EVE BUREAU-POINT is an anthropologist at the French National Center for Scientific Research (CNRS) in Marseille. She undertook her PhD and two periods as a post-doctoral research fellow in Cambodia on the circulation and appropriation of medical knowledge and technologies. Address correspondence to: Eve Bureau-Point, UMR 8562 Centre Norbert Elias, 2 rue de la charité 13002 Marseille, France. Email: eve.bureau-point@ univ-amu.fr 
CARINE BAXERRES is an anthropologist at the French National Research Institute for Sustainable Development (IRD), and a research fellow at MERIT, IRD, Université de Paris Descartes, Laboratoire Population Environnement Développement, Marseille. Since 2001, she has studied access to healthcare and global and local pharmaceutical markets, including the circulation, distribution, regulation and uses of pharmaceuticals in West Africa. Email : carine.baxerres@ird.fr

SENA CHHEANG is a pharmacist, Professor and Dean of Faculty of Pharmacy at the University of Health Sciences in Cambodia. He undertook a Diploma of Research in France (DUR), René Descartes Paris 5, from 2000 yo 2002. He was head of the Drug and Food Authority of Kampong Cham Province, was responsible for the drug management inspector's team 1995-2014, and was a member of the Pharmacovigilance Committee of the Ministry of Health. Email: sena_chheang@uhs.edu.kh 
Self-medication refers to an individual's behavior regarding the act of taking a remedy, whether pharmaceutical or not, on one's own volition. For the World Health Organization (WHO), self-medication —along with hygiene, nutrition, and lifestyle —is part of self-care; in other words, it is "what people do for themselves to establish and maintain health, prevent and deal with illness" (WHO 1998). Self-medication does not necessarily imply pharmaceuticals, but, in the context of most contemporary health systems where the biomedical model has established itself over other popular and traditional medicines, the meaning of self-medication is usually more limited and refers to pharmaceutical drugs and to the absence of control by certified biomedical professionals on their use. Thus, self-medication is based on the principle that some pharmaceuticals can be sold without a prescription, when consumers can use them safely and effectively by following the medicine's instructions and/or seeking advice from a pharmacist. Self-medication with pharmaceuticals is a growing phenomenon on an international scale (Baxerres 2013). While in some legal contexts, self-medication can only be practiced using medicines purchased in the presence of a pharmacist (Cambodia, France), in others, the role of the pharmacist has been eroded and OTC (over-the-counter) medicines are freely accessible (Ghana, United Kingdom, United States). Public health actors increasingly cite the ideology of democracy in health (Bureau and Hermann-Mesfen 2014) to justify policies that incentivize self-medication, by promoting individuals' responsibility in managing their health including through the use of pharmaceuticals. Moreover, policies to incentivize self-medication are also economically pragmatic, limiting clinical consultations and so reducing costs to states in covering medical expenses (Ruiz 2010).

Social science researchers have highlighted the limitations of these normative definitions by emphasizing the complexity of self-medication practices. Sylvie Fainzang shows that the inherent autonomy of these definitions is not limited to accepting or refusing to submit to biomedical professionals: "It implies that individuals must decide for themselves on 
a treatment based on their personal history, the information they have about their condition and what they identify as symptoms, and their perceptions about how health professionals treated their conditions in the past" (2012: 9). Furthermore, patients practice "disguised selfmedication" when they suggest that their doctors prescribe them certain products during a consultation that they will consume themselves or give to a family member (2012:3). For others, "there is only a thin line between self-medication and prescribed medication, and a doctor or nurse can never be sure a patient will take medicines exactly as they were instructed" (Van der Geest, Whyte and Hardon 1996: 165). Conversely, individuals may follow the advice of informal actors who are not authorized to prescribe and who may or may not be biomedical professionals (Jaffré and Olivier de Sardan 2003), but this may also be considered as adhering to a prescription. Self-medication and adherence to prescribed medication are not always mutually exclusive in practice.

Here, we have limited our investigation of self-medication to the use of pharmaceuticals. We consider these practices to be a product of a specific pharmaceutical system rooted in the specific history of pharmaceutical circulation in Cambodia. In our analysis, we consider this interconnection between self-medication, the social history of medicine, and the pharmaceutical system. By "pharmaceutical system," we allude to the modes of pharmaceutical procurement and distribution established by a state to ensure the availability of necessary medicines for population health in the country (Desclaux cited in Baxerres 2013: 31) and other less formal regulatory modes (Quet et al. 2018) of procurement and distribution.

The Cambodian health system, weakened by many years of political instability (particularly 1970-1991), has been slowly rebuilding. Despite economic growth and rising health indicators, improving health services remains a major objective. Social protection schemes, such as the Health Equity Fund, allow for free medical access to the poor in the 
public sector, but coverage remains relatively low (Jacobs and Price 2003). Although overthe-counter drugs have been covered by legislation since 2009 , the practice of self-medication with pharmaceuticals is widespread, resulting in drug resistance to antibiotics and antimalarials (Om et al. 2015). Further, contrary to the law, people can buy virtually any type of medicine without a prescription from retailers, making self-medication a major concern for public officials and research scientists. The principles of democracy in health are neither a priority nor the watchwords of national public health policies, except for certain global health issues (AIDS, tuberculosis) where patient autonomy is emphasized in confined spaces of care (Bureau-Point and Phan 2015).

Based on ethnographic research of the pharmaceutical system in Cambodia, conducted in one urban and one rural area between January 2015 and June 2016, we analyse the complex dynamics surrounding self-medication, highlighting the legacy of history and the logics of distribution and consumption where individuals bear the burden of covering their health expenses.

\section{METHODS}

The study on which we draw is part of the Globalmed program ${ }^{1}$ that is investigating pharmaceutical systems in three countries of the global South (Benin, Cambodia, and Ghana). This study was conducted in Phnom Penh, Cambodia's center of business and government and a transit hub for most medicines used in the country, and in a district in Battambang province, northwestern Cambodia. We spent one and a half years in the field to familiarize ourselves with key actors, gain the trust of some distributors, and gradually obtain the relevant information, using several qualitative and quantitative methods. Semi-directed interviews were conducted with 24 mothers from a broad range of socioeconomic backgrounds (three living on <US \$100 per month, ten on US \$100-400 per month, eight on US \$400-2000 per 
month, and three on >US $\$ 2000$ per month) to obtain information about them and other family members (spouse, children, others). Among the 24 mothers, 13 were from Phnom Penh and 11 from Battambang. The study targeted mothers because of the gendered role of women as caregivers.

In Phnom Penh, the mothers' average age was 33 years, in Battambang 26 years. In Phnom Penh, their professional status was wide-ranging (teacher, actor, daycare worker, caretaker, job seeker, non-governmental organization employee, stay-at-home mother, market-stall vendor), while in Battambang, women were primarily farmers, with a few civil servants and merchants. All families were Buddhist, except for two in Phnom Penh (one Muslim and one Protestant). Interviews with the mothers addressed the following topics: usual place for purchasing medicines, types of care sought (traditional, neo-traditional, popular and biomedical medicine) ${ }^{2}$ commonly used medicines in the family, and perceptions of diseases and health. We monitored these families' medicine consumption every two weeks for an average period of three and a half months. "Medicine" was defined broadly to mean any product consumed or used for health. We asked mothers to carefully memorize the various medicines used by family members and, when possible, to keep the labels. For each medicine consumed, we filled out a "medicine sheet" including the name of the medicine, its packaging, price, and source, where it was purchased, the person who recommended or prescribed the medicine, the person who used it, and the duration and reasons for treatment.

Interviews were also conducted with 57 people involved in the regulation and distribution of drugs: retailers in pharmacies and pharmacy depots, proprietors of medical practices (doctor, nurse, midwife), semi-wholesalers, ${ }^{3}$ health center staff, informal vendors working in unregistered pharmacies, small grocery shops, or directly in the street, medical sales representatives, representatives from state agencies, and representatives from "pharmaceutical companies." These interviews addressed: professional training, medicine 
distribution, source of medicines, laws governing the pharmaceutical system, and inconsistencies between laws and practices. We collected information about the sites where medicines are sold including their history, organization, operations, and the type of medicines distributed. We also observed onsite interactions between vendors and buyers in private outlets such as pharmacies, depots, and "houses that sell medicines," as explained below); this included 270 purchases in Phnom Penh and 121 in Battambang. We noted how patients access medicines (asking directly using the product's scientific, trade, or popular name; specifying symptoms/illness/organ; or presenting a prescription), and collected information about the products and the vendor (quantity/price/vendor profile). In general, accessing information about medicine distributors and vendors was challenging, given the sensitive nature of medical supply and distribution in Cambodia (Bourdier, Man and Res 2014). ${ }^{5}$

\section{HISTORY OF PHARMACEUTICALS IN CAMBODIA}

The pharmaceuticalization ${ }^{6}$ of Cambodian society started when the first pharmaceuticals were introduced during the French protectorate (1863-1953), supplementing other medicines in circulation particular to various medical paradigms (Theravada Buddhism, Ayurveda, Chinese medicine, and animist theories). Beginning in 1923, pharmacy health officials, also referred to as "pharmacists from Indochina," were trained at the Hanoi Faculty of Medicine in a fouryear program, and in Phnom Penh, four pharmacies were run by French pharmacists (Neou 1999). This era saw dynamic pharmaceutical manufacturing, with over 400 trademark drugs produced in Cambodia between 1940 and 1945 (Bonnemain 2008). After independence (1955), under King Norodom Sihanouk, health officers in pharmacy were trained at the Royal College of Medicine of Cambodia, and the first graduates became pharmacists after completing a five-year program in 1962. Since this period, pharmacists have mainly worked 
in Phnom Penh in pharmacies, while health officers have run depots in the provinces. Cambodians only purchased medicines after consulting their doctors, who had issued a prescription (Neou 1999). In the 1970s, the political situation began to deteriorate, and the collateral effects of the Vietnam War and the Lon Nol coup d'état weakened the country. Medicine prices rose (Ovesen and Trankell 2007). Next, the country fell under the Khmer Rouge (1975-1979), a radical Maoist communist regime based on an ideology promoting the purification of the Khmer people and an agrarian utopia aimed at self-sufficiency. Intellectuals and professionals, considered to be impure, were targeted first, and of the approximately 150 pharmacists trained from 1962, no more than 26 were alive in 1979 (Neou 1999). The Khmer Rouge did not reject Western medicine on the whole; the priority was to limit dependence on the outside world and to produce drugs within the country (Guillou 2009). In this context, the Khmer Rouge appropriated inventories from pharmaceutical companies and pharmacies, imported a few drugs, and implemented small-scale local production of vaccines and penicillin. However, pharmaceuticals were reserved for cadres and armed combatants. The remaining population consumed "neo-traditional" medicines, produced locally in cooperatives located across the country (Guillou 2009). These medicines were called aarj tunsaï by the people who consumed them, Khmer for "rabbit droppings" because of their resemblance. The Vietnamese intervention in 1979, marking the beginning of the Republic of Kampuchea, put an end to the Khmer Rouge regime. The priority was to remedy the lack of human resources by implementing a rapid training system: four years of training for pharmacy assistants, as occurred in Vietnam for health officers during the colonial period. Access to care and medicines was officially limited to the public sector within this state socialism. However, the scarcity of medicines following the reign of the Khmer Rouge fostered an environment in which the informal sector ${ }^{7}$ thrived, especially involving untrained 
vendors in and around urban and rural markets (Ovesen and Trankell 2007). This was the start of what Laragh Gollogly has called "pharmaceutical anarchy" (2002).

After the United Nations intervention in 1991 and a return to stability under the constitutional monarchy of the new Kingdom of Cambodia, hundreds of international organizations arrived. The country entered the market economy, and with this, the start of a long process of liberalization of the pharmaceutical system, characterized by an increase in the number of pharmaceutical companies (174 in 2010 to 308 in 2015 according to DDF), an increase in the number of local production compagnies (10 in 2010 to 14 in 2015 according to DDF), an increase in the volume of medicines in circulation (10 000 in 2010 to 12000 in 2015 according to DDF), and the development of a public and private distribution system dominated by the private sector (Neou 1999). In 2013, 80 percent of medicines circulated in the private sector (Men 2013), this pattern continues to the present.

The current pharmaceutical system bears traces of the French protectorate. The retail distribution system is based on French law; it grants a monopoly to the pharmacist, who must oversee drug importation, distribution and sales. The words "pharmacy" (pharmacie) or "depot" (dépôt), the official places for retail distribution discussed below, are still written in French on pharmacy storefronts (see Figure 1).

Insert Figure 1 about here

Academic programs in pharmacy and medicine are based on the French system. Many students complete internships in France where they become familiar with the medicines used there that they will later prescribe or distribute in their day-to-day practice in Cambodia. For a long time most imported medicines came from France (Ovesen and Trankell 2010): 50 percent of distributed medicines came from France in 1994. In 2015, however, according to the Department of Drugs and Food (DDF), medicines now come from Asian countries: India 
(31\%), Thailand (7\%), Korea (6\%), Vietnam (5\%), other countries (35\%), as well as France $(7 \%)$ and produced in Cambodia (9\%).

"French medicines" (thnam barang, thnam: medicine, barang: French) still appear to have the best reputation, and this category continues to carry weight in discourses. ${ }^{8}$ However while its French characteristics are significant, the current pharmaceutical system has been shaped by a range of influences. Wholesale distribution in particular does not fulfill the standards in force in France nor other former French colonies, such as Francophone West Africa where pharmaceutical legislation aligns closely with that of France (Baxerres 2013). Wholesale distribution seems more liberalized in Cambodia, involving numerous pharmaceutical companies: 308 in 2015, versus seven in France and five in Benin (Baxerres 2013). Wholesale distribution in Cambodia most resembles the system in the Englishspeaking world, such as the United Kingdom, United States, and Anglophone West Africa, and the companies are not legally bound, as in France, to distribute all of the country's authorized medicines (interview, pharmacist, Phnom Penh, July 2015). Drug prices are regulated by the free market.

In the 1990s, the state began to regulate the drug market. Three specific licenses were established for resale distribution: the first to pharmacists; to compensate for the country's shortage of pharmacists, the second and third licenses are, respectively, issued to assistant pharmacists to open type-A depots and retired health professionals to open type-B depots. Officially, the depots are authorized to sell a limited list of medicines; in practice, these limits are not taken into account. The national agency for pharmaceutical regulation-the current DDF - was created in 1994 and began to register medicines that same year. The first pharmaceutical law, still in force today, was introduced in 1996 and sets the general rules for manufacturing and distribution. Although law enforcement is a major challenge, since 2010, the government has intensified pressure on retailers to register with the Ministry of Health and 
apply for a license. With this, the number of places where informal sales take place has decreased considerably (Men 2013).

In the following section, we present the places people actually turn to when they want to purchase medicines. We will use self-medication in its public health meaning here to refer to the absence of any prescription from a health professional. In the last two sections, we focus more broadly on people's autonomy in medicine use, by discussing the interactions that develop between vendors and buyers in the various sites described.

\section{SELF-MEDICATION IN DESIGNATED SITES}

\section{FOR PHARMACEUTICAL DISTRIBUTION}

\section{Pharmacies and Depots}

The majority of medicines taken by family members in the study were obtained in a pharmacy or pharmacy depot. This trend, already highlighted in the literature (CDHS 2015), may be for several reasons. Firstly, as noted above, the client ${ }^{9}$ is able to obtain any medicine there without a prescription. Secondly, these sale points are widespread and so provide quick access. Vendors, including some health profesionals working in these sale points, are not familiar with the official list of OTC drugs and generally do not include them in their practices, with the exception of a small number of pharmacies in cities and tourist areas (Phnom Penh, Siem Reap, Sihanoukville and Kep) whose managers want to be known for applying best practice in pharmacy standards (presence of a pharmacist, air-conditioning, prescription medicines only sold with a prescription). At the time of this study, Phnom Penh had about 20 such pharmacies.

Many purchases in these sites fall under the narrow definition of self-medication. Based on the Cambodian list of OTCs, most medicines purchased without a prescription in pharmacies and depots that we counted during our bi-monthly monitoring of families were prescription medicines (84\% in Phnom Penh; 58\% in Battambang). Beyond prescription 
medicines sold without a prescription, nearly all sales could be considered self-medication since according to the law, a pharmacist, assistant pharmacist or retired health professional must supervise OTC sales in pharmacies and depots. However, as elaborated below, we found numerous non professional drug vendors working in these outlets. ${ }^{10}$ Further, in these sale points health profesionals often distributed medicines without consultation. In the rural study area, official drug distribution sites were temporarily given special status. These were neither pharmacies nor depots but "houses that sell medicines" (pteah louk osot ${ }^{11}$ in Khmer). According to a DDF representative and a provincial health representative (interviews, September 2015), this status was granted by the Provincial Health Department, at the time of regulatory efforts in 2010 , to allow official private structures to open despite the lack of trained health professionals able to take responsibility in remote areas. The owners of these sites were mostly nurses from the community health center; in parallel to their roles in the public sector, these nurses dispensed medicines privately outside of their work hours, although they sometimes did this also during their public sector shift. During their absence, we noted that these private structures remained open, and that an unqualified person from their family network continued to conduct sales. This phenomenon, known as "double practice," has developed in the 1980s, and includes most health professionals in the public sector both in Phnom Penh and Battambang. In cities, the lack of pharmacists in pharmacies is due less to lack of human resources and instead to the lack appeal to pharmacists to work in pharmacies. Most pharmacists, according to our interviewees, seek jobs with international organizations or pharmaceutical companies that are much more rewarding financially and professionally. The pharmacists we met in Phnom Penh explained that they "lend" their licenses to representatives of pharmacies or pharmaceutical companies in exchange for US\$100-150 per month. With certain discomfort, they explained that they rarely set foot on the premises for which they are officially responsible. "What use are all those years of 
pharmaceutical studies if it's just for a job earning between 150 and 300 US dollars per month that's usually performed by unqualified people?" remarked Sopheap, ${ }^{12}$ a pharmacist, aged 32, in Phnom Penh. These "pharmacies without pharmacists" has been described by Ovesen and Trankell (2007).

\section{Health Centers and Hospitals in the Public Sector}

Most of our interviewees in were critical of referral hospital and health centers. Waiting time to be seen is lengthy, and drug distribution in the public sector does not seem to meet patients' expectations. Various interviewees, from both urban and rural areas, claimed that "there's only para (paracetamol) at the health center," and "they don't have everything you need; there are frequent stockouts, and then we have to go buy medicines in the private sector." People with financial means generally avoid this sector or use it for specific reasons only: access to expensive medicines distributed for free (triple therapies for HIV or tuberculosis), reproductive health follow-up visits (contraceptives, vaccines for pregnant women or neonates), access to free treatment (for poor people with a fee-waiver card), or use of the ambulance transport system in an emergency. In these facilities, patients see a health professional before being sent to the in-house pharmacy with a prescription, and so access to medicines in this sector does not fall into the category of self-medication.

\section{Private Clinics and Consultation Rooms}

Private clinics are the responsibility of the Ministry of Health and are identified as having more than five hospital beds. According to our observations and interviews, medicines obtained in these facilities were prescribed by certified prescribers. Most clinics have either an in-house or an adjoining pharmacy, usually run by a family member of the owner, and there is a strong incentive for patients to buy their medicines from these facilities. Generally, our interviewees consider these places expensive because both the consultation with a 
professional and the medicines are subject to fees. Also, because they are located in urban areas, rural patients must cover transportation costs. Patients only consult them for serious problems, when they think access to a specialist and medical equipment is required.

Private consultation rooms are smaller than clinics and are the responsibility of municipal health departments. Many people use them, both in the city and countryside. Medicine distribution practices are similar to those in pharmacies and depots, and at first glance, many sales seem to fall under self-medication. The doctors, nurses, midwives and dentists who work there, along with other non-qualified vendors who replace them during their absences or assist them during peak times, take on the role officially reserved for pharmacists and gear their activities toward selling medicines. Health officials maintain that private consultation rooms may carry outpatient drugs for patient care; however, in practice, they have an arsenal of medicines sometimes equal to those of pharmacies and depots. Moreover, although they are not authorized to sell them, the opposite occurs: the staff at these facilities consider that while the consultation, which rarely takes place, is free, the medicine must be purchased. ${ }^{13}$ This is a prime example of the commodification of medicines (Whyte, Van der Geest, and Hardon 2002). These professionals and laypersons distribute medicines as quickly as pharmacies and depots, with limited conversations with the patient, as the following excerpts illustrate (Table 1).

\section{Insert Table 1 about here}

Can it be said that these distribution methods are "prescriptions" even though, strictly speaking, the professionals do not consult with their patients? In situations where health professionals respond to a patient's spontaneous request without taking the time to check their health status or properly performing a clinical diagnostic exam, the distribution fits our definition of self-medication. Our definition also applies when medicine is distributed by a non-qualified member of the health professional's social/familial network. 


\section{Non-Governmental Organizations (NGOs)}

People in poor areas of Phnom Penh sometimes have access to pharmaceuticals when doctors employed by NGOs visit and consult in these neighborhoods. The drugs are usually distributed free of charge. after a consultation with a doctor working for the organization. Sometimes the doctor writes a prescription when the medicine is out of stock. Spontaneous requests for medicines also occur within this distribution method, resulting in self-medication practices. However, in the slum area of Phnom Penh where we conducted our study, the NGO medical staff came only once a week, creating a perception among residents that this point of care only provided limited assistance.

\section{The Informal Sector}

In both Phnom Penh and rural areas, the families that we monitored mainly purchased their medicines in registered locations. In our follow-up, the use of medicines in the informal sector was minimal (one percent of medicine purchases). Only a few purchases of paracetamol were made in small grocery shops (Figure 2).

\section{Insert Figure 2 about here}

These purchases are another form of self-medication, in the narrow meaning of the term. Bypassing formal procedures, families may ask health professionals living nearby to make house calls, less for emergency reasons than for ease of access and confidentiality. Generally, professionals sell drugs during these visits, as they do when approached with spontaneous requests for these medicines.

Practices at the various distribution sites in Cambodia illustrate the limitations of the normative definition of self-medication. Self-medication, though prevalent in pharmacies and depots, is also found at the prescriber level in private medical practices and through distribution by NGOs and in the informal sector. Therefore, it appears inappropriate to 
consider self-medication in Cambodia solely in official sites - pharmacies and depots - that are authorized to supervise this practice.

\section{CLIENT PRACTICES: SELF-MEDICATION OR FOLLOWING A PRESCRIPTION}

We now turn to observe practices from a less restrictive perspective, in which self-medication is considered an expression of individual autonomy. Generally, autonomy is ubiquitous in seeking care and manifests outside medical recommendations in response to a specific health system, history, and representations of health.

\section{Drug Vendors}

Drawing on interviews and observations, in private medical practices, pharmacies, and depots, clients believe they are dealing with qualified health professionals who possess the medical expertise and proper pharmaceutical knowledge to meet their needs. Clients rarely know the professional status of those who treat them and frequently call the people they meet at these various health care points pet (a diminutive of kru pet: kru, master; pet, hospital, translated in English by "doctor" but used to designate all health professionals). Health professionals often own depots or pharmacies, and the vendors working alongside them who sell medicines are generally from their social and familial environment (a spouse, niece or nephew, cousins, son or daughter, or family friend). Regardless of their family status, they are perceived as pet, based on their somewhat remote relationship to biomedical knowledge, as health professionals acknowledged: "When one family member is pet, the others become pet also." Consequently, in popular perceptions, retailers provide both professional health consultations and medicines, and a consultation that does not result in dispensing medicine is generally perceived as useless. People usually have one or two preferred locations where they purchase medicines, based on prior experiences. A trusting relationship is established with the 
people who work there, built less on the status of the location and professionals than on interpersonal relationships and the perceived efficacy of the treatment received.

Several factors explain why the status of the sites and professionals ultimately plays a minimal role in building trust. Firstly, we mentioned that people hardly distinguish between private medical practices, pharmacies and depots. The law has designated pharmacies and depots by green crosses and private clinics and consultation rooms by blue ones. However, in practice the colors do not always comply with these standards (Figure 3), and seldom serve as a reference point for individuals to distinguish between these distribution points. More generally, the coexistence of two color codes in popular perceptions in Cambodia-until recently, no distinction was made between green and blue-partially explains why these color-coded crosses are inefficient. ${ }^{15}$ But patients in private consultation rooms and pharmacies feel that they are speaking to health professionals, and so this does not reflect a self-medication approach.

Insert Figure 3 about here

\section{Interactions between buyers and vendors}

While observing interactions between buyers and vendors (professional or not) in the various private sites, we noted that most purchases were made on the basis of explaining the symptoms, the name of the malady, or even mentioning an organ to the vendor, which they often associate with the term thnam. ${ }^{16}$ Buyers also asked for a special type of formulation, as we will explain below. In Table 2 we provide a few "semiological descriptions" (Jaffré and Olivier de Sardan 1999) used for medicines in Cambodia, corresponding to the main ailments that individuals face day to day, indicate the type of formulations that clients value, and provide some examples of pharmaceutical content commonly used for these ailments.

Insert Table 2 about here 
Except for a few widespread names such as para (paracetamol), amo (amoxicillin), ampi (ampicillin), $P$ (Phosphalugel ${ }^{\circledR}$ ) and calcium, most of ways that buyers asked for medicines help compensate for a lack of knowledge of drugs' scientific and trade names. While monitoring medicine consumption by families, we found that spontaneously asking vendors for a medicine by its specific scientific or trade name occurred 44 percent of the time in Phnom Penh and 35 percent in Battambang. If self-medication is understood as a spontaneous request for a medicine from a vendor, then the rates appear to be lower than when using the normative definition of self-medication (purchase of a prescription medicine without a prescription). As noted, 84 percent of depot and pharmacy purchases in Phnom Penh and 58 percent in Battambang can be classified as cases of self-medication, but depending on how self-medication is defined, the rates can vary significantly. The Globalmed study conducted in Benin and Ghana using the same methodology shows the opposite: the vast majority of clients spontaneously request a medicine that they want to purchase (65-80 percent in numerous sites that conduct retail distribution of pharmaceuticals in the two countries). For various reasons explained below, vendors in Cambodia maintain control of medicine sales.

\section{Layperson Influence in Using Medicines}

The consumer has influence on some aspects, such as treatment duration. One trend, not specific to Cambodia, is stopping treatment as soon as the patient feels better. Thus, the consumer frequently determines the treatment duration. At time of purchase, if clients do not specify the duration, many vendors (professional or not) ask them how long they want to take the medicine. Perceptions about health and the efficacy of medicines may explain this lay influence. Clients usually want to test the medicine on themselves before buying the full treatment. They buy enough for one or two days, explaining that they will return to get the 
remaining treatment if they feel an improvement. As illustrated by the concept of hiyang (compatible) in the Philippines (see Whyte, Van der Geest and Hardon 2002), emic perceptions suggest an interpretation of efficacy that differs from that of biomedicine. Although biomedicine widely assumes the universality of treatments, recurring emic perceptions worldwide suggest a different interpretation of efficacy. In Cambodia, according to Res (2017), the concept of korp (fit) illustrates these same emic perceptions. Economic reasons further explain why treatment duration is set by laypersons. Clients frequently show a specific amount of money in their hand, and vendors suggest a treatment based on this amount. In this case, the context is one of forced autonomy, whereby patients make decisions based on their capacity to pay. Moreover, most individual vendors respect clients' wishes to win their loyalty and not risk losing them to a competitor. However, vendors can and do influence consumer autonomy in other ways, as we explore below.

\section{Sales Strategies and Knowledge Acquisition}

Medicines as tablets or blister packs are rarely sold in their original packaging, but more often are sold in bulk in clear plastic bags sealed with a rubber band and containing several doses. This mode of formulation is not specific to non-professional vendors but is also practiced by health profesionals. In Khmer, these bags are called thnam psoam, literally "mixed medicines" and nicknamed "cocktails" in Cambodia both by researchers (Gryseels et al. 2013; Yeung et al. 2015) and in the media (Sassoon 2016). During our study, a few interlocutors told us that this practice directly derived from the practice of kru khmaer, which generally mixes different phytotherapeutic products. Public health officers criticize this because of the risks of overdosing and drug resistance. Frequently, vendors put two types of antibiotics, analgesics or anti-inflammatories in one bag. This phenomenon is also widespread in Laos (Newton et al. 2008); in Thailand, it has gradually diminished and disappeared 
(pers.comm., Supang Chantanavich, 2015). In Ghana, some "mixtures" appear similar to thnam psoam and were more common before.

In Cambodia, one bag usually corresponds to one dose (Figure 4). Rarely do vendors provide a single type of medicine per bag; rather the bags usually include three to eight different medicines, combining bulk tablets with blister tablets, whose quantity, price and colors vary depending on the vendor, client, urban or rural context, and health issue. Some vendors are reputed to compose thnam psoam with many medicines; others limit them to three or four. The thnam psoam have the distinction of being multi-colored, and retailers suggested that "adding some color" was important when preparing an "appealing thnam psoam." For example, red vitamin tablets had the double advantage of adding color and increasing the number of medicines without causing undue harm.

Insert Figure 4 about here

For vendors, the preparation of the thnam psoam allows them to unload the least expensive medicines (usually from Cambodia and India), although at times, especially in cities, clients request thnam psoam with "French medicines," which may increase the price eightfold. It also allows vendors to meet their clients' demands, a key point in any business activity. Generally, vendors have repeat customers and know their preferences, and try to guess the preferences of passing clients based on their appearance (deducing purchasing power through clothing) and their comments. Interactions between vendors and buyers are brief, and vendors manage with little direction from the patient to guide the treatment. From the vendor's viewpoint, one advantage of the thnam psoam is reducing the number of explanations; if the components were given separately, the vendor would have to explain each one to the consumer.

The thnam psoam are requested and/or sold for certain categories of health problems, such as pdassaï, ${ }^{14}$ toothache, stomach ache and diarrhea. Some retailers prepare bags in 
advance for these different pathologies, but arrange their displays so that they are not very visible from outside the point of sale. They fear inspectors' visits or being reported by potential competitors, regulators of best pharmacy practices, even researchers. Those who prepare the thnam psoam in advance usually sell in large quantities, for example, they make bulk sales to small dealers who redistribute them informally in the dynamic working-class neighborhoods of Phnom Penh where textile factories are located, for example, or in small shops in rural areas. The bags are usually prepared "on demand" in pharmacies, depots and private medical practices. Except for the very few retailers who distance themselves from these practices, denouncing them and explaining the disadvantages of thnam psoam to their clients, all retailers we met prepare them. Some argue that if they stopped, they would lose their clientele due to patients' high demand, explained below.

The thnam psoam are mainly composed of bulk medicines from boxes of 50 to 100 tablets with fairly uniform packaging (usually generics) placed under the counter (Figure 5). According to vendors, this prevents clients from identifying the packaging, therefore gaining their loyalty by guaranteeing that they will return if they like the treatment provided. Further, vendors frequently swap boxed medicines into other boxes or containers so that clients cannot identify them by name or appearance. One vendor, for example, explained to us how she arranges her drugs: "All of the most commonly used medicines are in bulk. I take them out and put them in the other boxes. It's a question of keeping clients, and beyond that, it's more convenient for making the thnam psoam" (Phnom Penh, April 2015).

\section{Insert Figure 5 about here}

For many consumers, the thnam psoam guarantees an effective treatment. Different explanations emerged from our study. "It's more effective to take the thnam psoam than one single medicine because when you're sick, there's always several health problems. So, there must be one medicine for each problem" (mother, Phnom Penh, February 2015). Local 
perceptions of efficacy sometimes dictate that the number of medicines should be proportional to the number of symptoms. For example, someone who has a headache, sore throat and fatigue will expect three different kinds of medicines. For others, consuming several medicines at the same time "helps you get better faster" (father, Battambang, March 2016). Moreover, although the price of thnam psoam can vary widely (US $\$ 0.25-\$ 3.00$ ), on the whole, it allows people to get several pills at an affordable price. In addition, consumer does not need to remember the dosage for each medicine, just the daily number of bags recommended by the vendor.

Although this distribution method may facilitate adherence, the consumer has no idea of the products being consumed. Furthermore, once the bags of thnam psoam are prepared, the patient has no way of knowing the contraindications or checking expiration dates. The speed of the exchanges also limits access to information. From our point of view, the distinction lies in the potential for individual empowerment, in the sense of access to knowledge about medicines, i.e., their names and their indications (expected effects). Thus, selling medicines through thnam psoam prevents individual empowerment and keeps consumers dependent on their vendor.

\section{CONCLUSION}

In this study, we revisit the definition of self-medication put forward by public health policies. From our point of view, self-medication - medicines purchased and used without a prior medical consultation - does not encompass the boundaries of the phenomenon where the biomedical standards of drug prescription and distribution are not applied. The public health definition places disproportionate responsibility on patients for their health, and minimizes the role of health professionals, institutional representatives and structural context. 
In this article, we took an approach based on individual autonomy, and considered the history and the current dynamics of drug circulation in a specific pharmaceutical system, so revealing the many meanings of self-medication. We consider that self-medication should be understood as both relational (i.e., undertaken in interactions with others who are seen as having medical knowledge and are in a position to provide medicines) and as pragmatic, in weak health systems where insurance coverage is low and people are poor. Clients and vendors find a "match" in which the autonomy of both the client and the seller are negotiated.

The consequence of the pharmaceuticalization of Cambodian society and the weight of history is that at the time of our study, many medicines are purchased without a prior medical consultation. The biomedical health system faces various challenges and where individuals bear the burden of covering their health expenses, and in this context drug distribution and specifically self-medication primarily take place in the private sector. Consumers are largely unfamiliar with the scientific and trade names of drugs, and drug vendors (professional or not) play a key role in controlling distribution through strategies that limit clients' ability to gain knowledge about medicines. Certain uses linked to popular perceptions about health and drugs certainly generate health risks (for example, deciding on the treatment duration).

As elsewhere (Baxerres 2013, Craig 2002, Granado et al. 2009), this popular knowledge is constructed in a syncretic way based on the transmission of traditional knowledge, experiences in health care facilities and exchanges with health professionals, and actors involved in pharmaceutical distribution. In Cambodia, the harsh political regimes that held power, particularly the Khmer Rouge, influenced the process for acquiring popular knowledge about pharmaceuticals and during this period, few people had access to pharmaceuticals. In 1979, there were only 26 pharmacists left, official production and distribution sites were destroyed. The disruptive effects on people's personal relationship to medicines has endured a "depharmaceuticalization" of Cambodian society during this period. 
In Cambodia, medicines remain primarily under the control of health professionals, but professional distributors are increasingly taking over that control. This has not resulted in a more rational use of products since most professional distributors, as we have seen, use pharmaceuticals as a lucrative "object" to revive economic activity, even if straying from the rules of medical practice. Thus, in contrast to the pharmaceuticalization process reflecting the increasing autonomous use of medicines (Egrot and Desclaux 2015), in Cambodia the marketorientation of the provision of pharmaceuticals has left individuals with minimal control of their own health.

\section{Notes}

1. For further information see http://globalmed.ird.fr/la-recherche/contexte-et-objectifs

2. Although we focus on pharmaceuticals in this article, in the study we examined the range of health practices people use: traditional medicine (Khmer medicine founded in the scholarly tradition transmitted through texts, primarily based on using medicinal plants and officially recognized by the Ministry of Health); popular medicine, meaning syncretic home remedies based on a combination of lay knowledge, knowledge of Khmer medicine and/or biomedicine; and "neo-traditional medicine," which uses products, often phytotherapy, from a variety of therapeutic traditions, with standardized, specific contents and packaging.

3. Semi-wholesalers purchase their supplies from "pharmaceutical companies," sell wholesale or retail, and have a pharmacy license. They are not authorized to import, yet our interviews indicate they do so illegally, mostly from neighboring countries such as Vietnam and Thailand. Sometimes these semi-wholesalers run an import company alongside their pharmacy. 
4. In local use, the term "pharmaceutical company" refers both to local medicine manufacturing firms and medicine import-export and distribution companies. They have a special license from the Ministry of Health to import and export medicines.

5. The drug market is related to health but is also a lucrative market. Different actors along the biomedical medicine circulation chain use them as a resource to enhance their personal income. Biomedical standards are not always respected, and actors try to keep their practices secret so that ordinary citizens are unable to discern that they are evading the law.

6. This concept, analysed by Egrot and Desclaux (2015), refers to the increase in the volume of pharmaceuticals in circulation and their increasingly predominant place in society.

7. Pharmaceutical practices outside of frameworks are defined by the state and the country's health officials.

8. This category is subjective and is not strictly related to the source of medicines. Drugs considered to be in this category by both clients and vendors may come from France but also from Korea or Germany. Generally, these are expensive drugs, similar to the category "French drugs" or "pharmacy drugs" described for Benin (Baxerres 2013).

9. In private pharmacies and depots, most drug vendors called consumers neak ting (buyers) or client pniou. In this article we use the term "client" to refer to the consumers of these private outlets. In hospitals and health centers, health professionals called them neak tchum ngeu (patient).

10. Generally, one of the vendors in these retail places has completed three months of training, organized by the Provincial or Municipal Health Department of the Ministry of Health, but this does not replace the training received by health professionals authorized to distribute medicines. 
11.There is no universally recognized phonetic transcription system in Cambodia; in this article, we used a liberal transcription system to facilitate the pronunciation of Khmer words for an English speaker.

12. To protect the subjects' privacy and confidentiality, pseudonyms are used throughout.

13. As explained by a member of DDF (Phnom Penh, August 2018), the Ministry of Health is in the process of solving this problem.

14. Pdassaï refers to a "nosologic popular entity" (Jaffré and Olivier de Sardan 1999) generally translated as "flu" and "common cold;" Cambodians use the word pdassaï for different disorders such as runny nose, headache, sore throat, cough, fever and sneezing.

15.According to several local sources, the color green did not exist for a long time. One health professional remarked that "traditionally, we say that the rice fields or the trees' leaves are blue" (Interview, Phnom Penh, March 2015).

16. Although the word thnam is commonly translated by "medicine," it is a generic term that covers a vast lexical field. "Hair dyes," "nail polish," “wax," "tobacco," "pesticides," "paint" and "poison," for example, are also referred to as thnam. According to Michel Antelme and Gerard Diffloth (linguists specializing in Mon-Khmer languages), the word thnam is derived from the Khmer word dam, from the verb "to boil." This term refers to a combination of various products that have been processed using various methods (boiling, drying, cooking, crushing and grinding) to produce a final product that may not only be used to heal or embellish, but also to kill or destroy.

\section{ACKNOWLEDGMENTS}

The project was approved by the National Ethics Committee for Research in Health of Cambodia (466, NECHR). We thank all those interviewed during this research project for the time they generously gave us. We also thank Maurice Cassier who led us to the 
conceptualization of "depharmaceuticalisation" for the situation of Cambodia during discussions at an internal Globalmed project meeting in September 2016, held in Paris.

\section{FUNDING}

This project received funding from the European Research Council under the European

Union's Seventh Framework Programme (FP7/2007-2013)/ERC grant agreement no. 337372.

\section{REFERENCES}

Baxerres, C.

2013 Du médicament informel au médicament libéralisé : une anthropologie du médicament pharmaceutique au Bénin. Paris, France: Les Éditions des Archives Contemporaines.

Bonnemain, B.

2008 Colonisation et pharmacie (1830-1962): une présence diversifiée de 130 ans des pharmaciens français. Revue d'histoire de la pharmacie 359: 311-34.

Bourdier, F., B.Man and P. Res

2014 La circulation non contrôlée des médicaments en Asie du Sud-Est et au Cambodge.

L'espace politique 24 (3). doi: 10.4000/espacepolitique.3220

Bureau, E. and J. Hermann-Mesfen

2014. Les patients contemporains face à la démocratie 
sanitaire, Introduction au numéro thématique sur le «patient contemporain »,

Anthropologie \& Santé 8. URL : http://anthropologiesante.revues.org/1342

Bureau-Point, E. and S. Phan

2015 The structural violence of patient participation in Cambodian HIV services.

Qualitative Health Research 26 (9): 1263-74.

\section{CDHS}

2015 Cambodia Demographic and Health Survey 2014. Phnom Penh, Cambodia: Cambodia Demographic Health Survey 327.

Craig, D.

2002 Familiar Medicine: Everyday Health Knowledge and Practice in Today's Vietnam. Honolulu, HI: University of Hawaii Press

Egrot, M. and A. Desclaux.

2015 Anthropologie du médicament au Sud: la pharmaceuticalisation à ses marges. Paris, France : L’Harmattan.

Fainzang, S.

2012 L'automédication ou les mirages de l'autonomie. Paris, France: Presses Universitaires de France.

Gollogly, L.

2002 The dilemmas of aid: Cambodia 1992-2002. The Lancet 360: 793-98.

Granado, S., L.Manderson, B.Obrist and M.Tanner.

2009. The moment of sale: Treating malaria in Abidjan, Côte d'Ivoire. Anthropology and Medicine 16 (3): 319-331.

Gryseels, C., S.Uk, A.Erhart, R.Gerrets, V.Sluydts, L.Durnez, J.M.Ribera, S.Hausmann Muela, D.Menard, S.Heng, T.Sochantha, U.D’Alessandro, M.Coosemans, K.Peeters Grietens 
2013 Injections, cocktails and diviners: therapeutic flexibility in the context of malaria elimination and drug resistance in Northeast Cambodia. PLoS One 8 (11). doi : 10.1371/journal.pone.0080343

Guillou, A. Y. 2009 Cambodge: soigner dans les fracas de l'histoire. Paris, France: Les Indes savantes.

Jacobs, B. and N. Price.

2003 Community participation in externally funded health projects: lessons from Cambodia. Health Policy and Planning 18 (4): 399-410.

Jaffré, Y. and J.P. Olivier de Sardan

1999, La construction sociale des maladies, les entités nosologiques populaires en Afrique de l'Ouest. Paris, France: Presses Universitaires de France.

2003 Une médecine inhospitalière. Paris, France: Karthala.

Men, C.R.

2013 Safety of medicinal products in Cambodia: Assessment of the pharmacovigilance system and its performance. Submitted to the US Agency for International Development by the Systems for Improved Access to Pharmaceuticals and Services (SIAPS) Program. Arlington, VA: Management Sciences for Health.

Neou, S.L.

1999 Contribution à l'étude de l'évolution du système pharmaceutique au Cambodge. Phnom Penh, Cambodia: Université des Sciences de la Santé.

Newton, P.N, C.Y.Hampton, K.Alter-Hall, T.Teerwarakulpana, S.Prakongpan, R. Ruangveerayuth, N.J. White, N.P.J. Day, M.B. Tudino, N. Mancuso and F.M.Fernandez 
2008 Characterization of "Yaa Chud" medicine on the Thailand-Myanmar border: Selecting for drug-resistant malaria and threatening public health. American Journal of Tropical Medicine and Hygiene 79 (5):662-669.

Om, C., M.L. McLaws, E.Vlieghe, F.Daily and J.C.McLaughlin 2015 Cambodia: the first national study of antibiotic prescribing and resistance using mixed methods approach. Antimicrobial Resistance and Infection Control 4(1): 183.

Ovesen, J. and I.B. Trankell

2007 Pharmacists and other drug-providers in Cambodia: identities and experiences. In Medical Identities: Health, Well-Being and Personhood. K. Maynard ed. Pp. 36-60, Oxford, UK: Berghahn Books.

2010 Cambodians and their Doctors. Copenhagen, Denmark: NIAS Press.

Quet, M., L. Pordié, A. Bochaton, S. Chantavanich, N. Kiatying-Angsulee, M.Lamy and P. Vungsiriphisal

2018 Regulation multiple: Pharmaceutical trajectories and modes of control in the ASEAN. Science, Technology and Society 23 (3): 485-503.

Res, P.

2017 Social and cultural complexities of anti-malarial drug circulation: an ethnographic investigation in three rural remote communes of Cambodia. Malaria Journal 16:428.

Ruiz, M.E.

2010 Risks of self-medication practices. Current Drug Safety 5(4): 315-23.

Sassoon, A. M.

2016 Cautious optimism as malaria drug cocktail makes a comeback. Phnom Penh Post 25 February.

Van der Geest, S., S.R. Whyte and A.Hardon 
1996 The anthropology of pharmaceuticals: a biographical approach. Annual Review of Anthropology 25:153-178.

WHO

1998 The role of the pharmacist in self-care and self-medication. Report of the 4th WHO Consultative Group on the Role of the Pharmacist. The Hague, The Netherlands, 26-28 August 1998. Geneva, Switzerland: World Health Organization.

Whyte, R.S., S. van der Geest and A.Hardon

2002 Social Lives of Medicines. Cambridge, UK: Cambridge University Press

Yeung, S., H.L.S.Lawford, P.Tabernero, C.Nguon, N.Albert van Wyk, N. Malik, M. DeSousa, O. Rada, M. Boravann, P. Dwivedi, D.M Hostetler, I. Swamidoss, M.D. Green, F.M. Fernandez and H. Kaur.

2015 Quality of antimalarials at the epicenter of antimalarial drug resistance. American Society of Tropical Medicine and Hygiene 92(Suppl 6): 39-50. 